intervals or larger applications at less frequent intervals. Apparently any concentration within the range defined for the lower limits of about half a pound, and the upper limit of about two pounds per 16 cubic feet of water, gives satisfactory results. This means that the stirring in of additions of nutrients was not necessary ; the mixture was merely added at one point. Obviously there is a practical limitation to the distance salts will diffuse and consequently appropriate means must be employed where large basins are used.

A field of $1 / 100$ acre area planted to potatoes produced a yield of $24 \cdot 65$ bushels, or 1,479 pounds (Fig. 4) ; $40 \mathrm{lb}$. of chemicals was used. This experiment was in 1934. In subsequent trials each year thereafter, the above-stated large yields were not obtained; apparently certain features of the techniques, ideal in 1934, did not produce ideal growing conditions in the subsequent tests. I believe, however, that the technique can be designed to obtain consistent results with the potato.

The retail market price of the chemical used in largest amounts, and the most costly, namely potassium nitrate, was 70 dollars per ton. Chemicals were of the grade used in compounding fertilizers for land.

The greatest item of cost in crop production by hydroponics is the investment in basins. Also the cost of the chemicals will be a major item in some crops. For example, about two pounds of chemicals were required to produce four pounds of dry wheat grain. Even though the yield per unit area of water surface in basins of the size mentioned for tomatoes was exceptionally high (computed to acre basis it was 142 bushels), the ratio of the quantity of plant food required (at first glance one may think this quantity too high ; the weight of oxygen accounts for the apparent large quantity of plant food required) to that of yield obtained makes the cost of production of wheat and other crops that are predominantly 'dry matter' prohibitive by water culture under present conditions. Crops the marketable products of which are characterized by high water, starch, or sugar content, give promise in an economic appraisal of production by hydroponics.

It is, of course, not inconceivable that industry may develop and manufacture equipment at markedly greater economy than prevails at present, thereby increasing the number of crops that can be grown economically.

There are no specific formulæ or cultural techniques that can be prescribed to be followed too literally because of the somewhat unknown character of the materials and equipment that will be used; cultural technique must be designed to meet the conditions where the crops are grown. The principle of making the adjustments, the elucidation of the physiological basis for all features of the method, together with concrete description and data of experimental plants, need to be made available for the guidance of prospective hydroponicists. To provide this is the programme of research now being pursued.

\footnotetext{
1 Gericke, W. F., "Aquiculture-A Means of Crop Production", Amer. J. Bot., 16, 8̈62 (1929).

2 Gericke, W. F. "Hydroponics-Crop Production in Liquid Culture Media", Science, 85, 177 (1937).
}

\title{
Centenary of the Atlantic Steam Ferry
}

$I^{N}$ April 1838, the paddle steamer Sirius, 703 tons gross, won for herself the distinction of being the first vessel to cross the Atlantic Ocean under continuous steam power. To celebrate the centenary of this notable achievement, a special exhibition, "One Hundred Years of Transatlantic Steam Navigation", is being held at the Science Museum, South Kensington, and will be open until mid-September, to show in outline the developments that have marked the growth of this service. An illustrated handbook bearing the same title (London: H.M. Stationery Office. $6 d$. net) prepared by Mr. H. P. Spratt, the Museum officer responsible for the organization of the exhibition, gives a brief account of the history of the Atlantic steam ferry together with descriptive and historical notes on each of the steamships represented. These exhibit the striking developments which have taken place in naval architecture and in the methods of steam propulsion.

The change from wooden hulls, first to wrought iron construction and finally to steel, is exemplified in the size of the vessels and in new methods of construction. Paddle wheel propulsion gave way to single screws; twin, triple and quadruple screws followed in quick succession. The early engines derived most of their power from the condensation of the steam, and the nature of the evolution was first to simple expansion engines and then to compound, triple and quadruple expansion engines which, in their turn, have been superseded by the Parsons direct-drive, then single-reduction and now double-reduction turbines. It is to be remembered that each of these developments has 
been due not only to the progress of design but also to the improvements in ancillary departments, such, for example, as the manufacture and treatment of steel and other materials and in the production of accurately eut gears. As a means of visualizing the increase in size of the vessels, it is pointed out that the hull of the Britannia-the first of the Cunarders, 1,156 tons, built in 1840 at Greenock-could be fitted into the restaurant and foyer of the R.M.S. Queen Mary.

A visit to the exhibition is most instructive, as it epitomizes in the models which have been gathered together from various sources these and other aspects of the technical developments which the century has witnessed. A visit is the more desirable in that such an opportunity of seeing so many closely related models in so favourable a setting can only occur at rare intervals. As the models are, with a few special exceptions, to the same scale of 1 to 48 , it is possible to obtain a clear idea of the relative sizes and forms of these historic vessels. Among them are several foreign ships, notably the Bremen, the Conte di Savoia, and the Normandie, while another exhibit which has a special importance as the representative of steam's competitor in ship propulsion is the model of the Swedish diesel motor-liner Gripsholm. The Conte di Savoia, built at Trieste in 1931, was the first Atlantic liner to be fitted with gyroscopic stabilizers. These were made in England and the installation is calculated to limit the roll of the ship to $3^{\circ}$ on either side of the vertical.

As to which is the most interesting vessel represented, opinions differ, but the Great Eastern (1858) has some claim as being a premature leviathan conceived and built forty years or so in advance of practical experience. She was designed by Brunel and was about five times the size of any then in use. Built at Millwall, many unsuccessful attempts were made to launch her, and finally she was launched sideways into the Thames. A unique feature was that she was propelled both by paddle wheels and a screw propeller. The paddle engines of 3,411 I.H.P. had four oscillating cylinders and received steam at $24 \mathrm{lb}$./in. ${ }^{2}$ from four double-ended tubular boilers of box pattern. The screw engines of 4,886 I.H.P. had four horizontal direct-acting cylinders and received steam at $25 \mathrm{lb}$./in. ${ }^{2}$ from six double-ended tubular boilers. Though she had no commercial success as a liner, she did most valuable work between 1865 and 1873 in laying a number of submarine cables. Not until the Oceanic was built in 1899 was the size of the Great Eastern exceeded.

As a further mark of the importance of the occasion, a lecture entitled "The Centenary of Transatlantic Steam Navigation" was delivered before the Newcomen Society at the Science
Museum on March 16 by the president, Engineer Captain E. C. Smith, in which he dealt particularly with the construction and experiences of the early vessels on this service. Prior to 1838, many voyages across the Atlantic had been made by steam-engined vessels, but so far as it is known, all were made partly under sail. The first three to cross by steam power were the Sirius, built for the London and Cork service, which arrived off New York on April 22, 1838, the Great Western, built for the Atlantic service, which arrived on the next day, and the Royal William, also built for the Atlantic, which after some misfortunes completed the crossing on November 23. These vessels were, in a sense, sailing ships, as they carried sail and took advantage of the wind, but they were intended when necessary to steam against wind and sea. Therefore, although in effect sailing ships fitted with engines, they embodied important constructional modifications so that they could carry the machinery stresses and bear the severe shocks inevitable in a seaway. Sleepers or platforms were built in to carry the boilers and engines, strong beams were necessary to support the paddle shafts and the sponsons housing the paddle wheels. Sir Robert Seppings, surveyor to the Navy, was responsible for many of the devices adopted, and it was he who introduced a method of fitting the frames close together and caulking them to form a solid hull before the external planking was fixed. He also devised an arrangement of internal diagonals, which later took the form of diagonal iron bars, so as to make the hull a rigidly trussed structure.

Early engines were very similar to the land engines made by Boulton and Watt, of the two cylinder side-lever type with cranks at right angles, and used steam at a pressure of $2-5 \mathrm{lb}$./in.2 Condensers were essential at first as the bulk of the power was derived from the vacuum; later they were discarded and afterwards were reintroduced. Sea water was used in the boilers, which were practically rectangular tanks with internal flues. It was an important duty of the engineer to keep the density of the water low to prevent incrustation. Three methods were in use, the earliest being to stop the engines every third or fourth day, empty the boilers and refill from the sea. This was superseded by frequent blowing down which, in turn, gave place to the use of brine pumps.

The reprint of the lecture contains extracts from the "Field Papers" preserved in the Science Museum Library, which give much information not obtainable elsewhere on this subject.

A contemporary view of the prospects of the Atlantic crossing under steam appears on p. 566 of this issue. 